\title{
PEACH, a smartphone- and conversational agent-based coaching intervention for intentional personality change: study protocol of a randomized, wait-list controlled trial
}

Mirjam Stieger ${ }^{1 *}$, Marcia Nißen ${ }^{2}$, Dominik Rüegger ${ }^{3}$, Tobias Kowatsch ${ }^{4}$, Christoph Flückiger ${ }^{5}$ and Mathias Allemand ${ }^{1}$

\begin{abstract}
Background: This protocol describes a study that will test the effectiveness of a 10-week non-clinical psychological coaching intervention for intentional personality change using a smartphone application. The goal of the intervention is to coach individuals who are willing and motivated to change some aspects of their personality, i.e., the Big Five personality traits. The intervention is based on empirically derived general change mechanisms from psychotherapy process-outcome research. It uses the smartphone application PEACH (PErsonality coACH) to allow for a scalable assessment and tailored interventions in the everyday life of participants. A conversational agent will be used as a digital coach to support participants to achieve their personality change goals. The goal of the study is to examine the effectiveness of the intervention at post-test assessment and three-month follow-up.
\end{abstract}

Methods/Design: A 2x2 factorial between-subject randomized, wait-list controlled trial with intensive longitudinal methods will be conducted to examine the effectiveness of the intervention. Participants will be randomized to one of four conditions. One experimental condition includes a conversational agent with high self-awareness to deliver the coaching program. The other experimental condition includes a conversational agent with low selfawareness. Two wait-list conditions refer to the same two experimental conditions, albeit with four weeks without intervention at the beginning of the study. The 10-week intervention includes different types of micro-interventions: (a) individualized implementation intentions, (b) psychoeducation, (c) behavioral activation tasks, (d) self-reflection, (e) resource activation, and (f) individualized progress feedback. Study participants will be at least 900 Germanspeaking adults (18 years and older) who install the PEACH application on their smartphones, give their informed consent, pass the screening assessment, take part in the pre-test assessment and are motivated to change or modify some aspects of their personality.

Discussion: This is the first study testing the effectiveness of a smartphone- and conversational agent-based coaching intervention for intended personality change. Given that this novel intervention approach proves effective, it could be implemented in various non-clinical settings and could reach large numbers of people due to its lowthreshold character and technical scalability.

Keywords: Intentional personality change, personality change intervention, coaching intervention, smartphone, conversational agent

\footnotetext{
*Correspondence: m.stieger@psychologie.uzh.ch

'Department of Psychology and URPP Dynamics of Healthy Aging, University

of Zurich, Andreasstrasse 15, 8050 Zürich, Switzerland

Full list of author information is available at the end of the article
}

(c) The Author(s). 2018 Open Access This article is distributed under the terms of the Creative Commons Attribution 4.0 International License (http://creativecommons.org/licenses/by/4.0/), which permits unrestricted use, distribution, and reproduction in any medium, provided you give appropriate credit to the original author(s) and the source, provide a link to the Creative Commons license, and indicate if changes were made. The Creative Commons Public Domain Dedication waiver (http://creativecommons.org/publicdomain/zero/1.0/) applies to the data made available in this article, unless otherwise stated. 


\section{Background}

There is a recent debate in personality science whether and how personality traits can be intentionally modified or changed over short periods of time by intervention efforts. Although available research suggests that most people want to change or modify some aspects of their personality [1-3], psychological interventions for intentional personality change are almost lacking. Only a few studies have examined intentional personality change over shorter periods of time [4-6]. These very few existing studies are promising and suggest that intended trait change in a desired direction is possible. However, it is still an open question whether personality change can be maintained or rather reflects temporary changes that revert over time. This protocol describes a study that will test the effectiveness of a non-clinical psychological coaching intervention for intentional personality change that focuses on the Big Five personality traits, i.e., neuroticism, extraversion, openness to experience, agreeableness, and conscientiousness.

\section{Conceptual Framework of the Intervention}

Since intervention efforts for intended personality change are in their infancy, conceptual frameworks are needed to develop theory-driven intervention programs. One approach would be to carefully develop specified treatments/ treatment guidelines for changing particular personality traits. The other approach would be to develop interventions based on more general (common) intervention principles [7]. The present coaching intervention is based on a general (common) change mechanisms intervention framework. General change mechanisms are assumed to be responsible for intermediate changes in someone's characteristics, skills, experiences, and behaviors, and eventually lead to improvements in the ultimate outcome or targeted goal of an intervention. Allemand and Flückiger [7] argue that four empirically derived general change mechanisms from psychotherapy process-outcome research [8-11] provide useful heuristic principles for intentional personality change interventions and help to maximize the effectiveness of intervention efforts. The four mechanisms are: (1) actuating discrepancy awareness, (2) targeting thoughts and feelings (insight), (3) targeting behaviors (practice), and (4) activating strengths and resources. These mechanisms highlight different perspectives of the immediate individual psychological outcomes and are highly connected with each other [12]. In order to target those general change mechanisms and to promote the change process, the coaching intervention includes several micro-interventions. Micro-interventions (specific tools and techniques) are small interventions that are essential in helping individuals to modify or change trait-related experiences and behaviors in concrete real-life situations and help to maintain the change process [13].

\section{Actuating discrepancy awareness}

The first change mechanism focuses on the awareness of differences between the actual and the desired personality, which might facilitate the change process. The idea is that personality traits can be most effectively targeted and altered while people explore potential gaps between their actual and desired personality (cf. [14]). Examples of micro-interventions that target this change mechanism are (a) the motivational interviewing approach, (b) miracle questions, and (c) individualized progress feedback. The motivational interviewing approach [15] serves to counterbalance advantages and disadvantages of change and might eventually enhance individual change motivation. By writing down pros and cons of the actual and desired behavior and experience, people can evaluate the gap between their actual and desired personality. Miracle questions help people to think about their future goals and their desired personality and thus actuate discrepancy awareness between the actual and the desired personality. Miracle questions are basically thought experiments, which ask people to imagine their desired future and personality [16]. Individually tailored progress feedback is one of the most commonly used change techniques in smartphone-based health interventions [13] that helps people to focus on their discrepancy awareness.

\section{Targeting thoughts and feelings to realize insight}

The second mechanism emphasizes reflective processes, which may promote the personality change process by helping individuals to reflect their thoughts, feelings, and behaviors in a more systematic way. The following five micro-interventions are known to be effective to activate this change mechanism: (a) systematic reflection, (b) psychoeducation, (c) observational learning, (d) introspection, and (e) identification of situational/contextual triggers. Systematic reflection is a micro-intervention that helps people to learn from experiences including failures and successes [17]. Changing aspects of one's personality is hard and is related to experiences of failures. Systematic reflection helps to focus on the goal rather than on emotional reactions after a failed task. To promote the change process, it is also important to understand own beliefs and expectations. Since people may have different self-theories about the changeability of different aspects of personality [18], fostering the knowledge transfer about personality change in the form of psychoeducation may further promote the change process. Psychoeducation is a prominent tool in cognitive behavioral therapy [19]. Other micro-interventions, which also target thoughts and feelings, are the observation and modeling of others' behaviors (observational learning) [20,21], watching one's own behaviors, thoughts, and feelings (introspection) [21, 22], and identifying situational and contextual triggers (e.g., 
people, society, surroundings; [23]). Being aware of situational and contextual triggers, which are connected to the desired or actual behavior, can actually help to show desired behaviors more often and to avoid actual behaviors [23].

\section{Targeting behaviors to realize practice}

This mechanism focuses on learning and reinforcing new behaviors and skills, such as compensatory or coping skills, and to behave in new roles. To achieve change goals, individuals should gradually increase engagement in activities and new behaviors connected to their change goals. Two micro-interventions are included in the intervention to target this change mechanism: (a) implementation intentions and (b) behavioral activation. Generating implementation intentions in the form of specific "if-then plans" can lead to better goal attainment and help individuals in habit formation [24]. This micro-intervention was successfully used in previous intervention work for intentional personality change [5]. Behavioral activation tasks help individuals to perform novel behaviors and activities. Behavioral activation is based on principles of reinforcement and learning theory and was originally developed for the treatment of depression [25]. Magidson and colleagues' [26] suggest this micro-intervention also for intentional personality interventions and used it in their case study.

\section{Activate strengths and resources to realize strengths- orientation}

This change mechanism capitalizes on individual and interpersonal strengths and resources. Resources might be related to personal skills and capabilities, motivational readiness and preparedness for change, as well as social support. Micro-interventions identified to target this mechanism include (a) organizing a change team, (b) keeping a diary of strengths and resources, (c) using the tree of resources, and (d) thinking about future plans, dreams and hopes. An informed change team, including significant others such as friends and family members can provide social support throughout an intervention and help people to attain their change goals [27]. Keeping a diary of strengths and resources [28] or to write down individual resources inside the tree of resources $[8,29]$ can further promote the change process by reflecting about personal strengths and positive aspects of life. Another micro-intervention activates individuals' resources and enhances change motivation by thinking about future plans, dreams and hopes by getting asked questions derived from the life story interview approach [30].

\section{Smartphone-Based Coaching Interventions}

Smartphones provide a powerful tool set for psychological and behavioral micro-interventions for several reasons [31-38]. First, smartphones are ubiquitous with increasingly powerful technical abilities and make sophisticated micro-interventions appealing and widely applicable. Second, unlike desktop computers, laptops or tablets, smartphones are nearly always with the person. Third, people often have a positive emotional attachment to and daily routines in dealing with their smartphones, which can reduce the barriers to adoption and increase acceptance of micro-interventions. Fourth, the combination of powerful technical abilities of smartphones and their proximity to their owners offers the ability to detect useful context information that can be used to individualize interventions. Moreover, context awareness features enabled through sensing and phone-based personal information allows creating just-in-time micro-interventions that provide users with support at times when that support is most needed. Finally, interventions using smartphones are scalable, cost-effective, low-threshold, applicable to a wide variety of participants and show promising retention rates. For example, a recent study in the public health context found that owning a smartphone "was not a major barrier to study participation for most respondents [...] including those who were unemployed", i.e. with a low socio economic status [39]. In another recent study, retention rates of smartphone-based interventions are promising as participants had eight conversational turns with a smartphone-based chatbot per day on average over the course of six months $[40,41]$.

\section{The talk-and-tools-paradigm}

Smartphone interfaces also enable the application of the so-called talk-and-tools paradigm [42, 43]. That is, smartphones are able to offer scalable communication features with the help of conversational agents (the "Talk", e.g., for motivational interviewing purposes), i.e., computer programs that imitate a conversation with a human being [44-47]. In contrast to popular voice-based conversational agents such as Amazon's Alexa, Apple's Siri, text-based conversational agents (often called "chatbots") are so far less prominent. Promising examples include Florence (getflorence.co.uk), Lark (web.lark.com) or Woebot (woebot.io). In contrast, interfaces of smartphones can also be used to deliver a broad range of "Tools", i.e., the building blocks of micro-interventions (e.g., keeping a diary of resources, a reminder for individual implementation intentions or the delivery of psychoeducation video clips). The application of this talk-and-tools paradigm can not only complement and extend existing face-to-face counseling sessions to the everyday life of individuals, but it can also provide new means to offer smartphone-based coaching interventions in a scalable fashion where a personal coaching approach is not feasible due to limited reach, personnel or budget. 


\section{Design of conversational agents}

Due to limited evidence on effective designs of text-based conversational agents on mobile devices [48, 49], it is essential to study design features of conversational agents and how they help individuals to reach their goals. Conversational agents are designed to interact with a human - like a human. The Computers as Social Actors theorem by Reeves and Nass [50] confirms that individuals apply social behaviors and heuristics typical for social interactions with other human beings to interactions with computers - and conversational agents.

Research in the field of counselling psychology and psychotherapy has shown that working alliance, a collaborative quality and the degree to which health professionals and patients engage with each other, is associated with the therapeutic process and robustly linked to treatment success in face-to-face therapy as well as in online therapy $(r=.28$; [51]) $[52,53]$. The concept of working alliance can be adapted to the "relationship" between individuals and conversational agents and their interactions (e.g., quality and length of messages exchanged or frequency of interactions). It can be expected, that when a conversational agent takes over the role of a communication partner and embodies a digital coach, its communication style and role will affect relationship-building processes and, in part, treatment success (e.g., [54, 55]).

Hence, it can be assumed that the choice of specific verbal cues will increase an individual's working alliance with a conversational agent. The present conversational agent-based intervention will focus on one specific verbal cue, namely whether the chatbot can refer to itself using the first-person pronoun "I". The use of "I" automatically implies a sense of human self-awareness or self-concept by the chatbot [56], making it more anthropomorphic and relatable, than a conversational agent without a self-concept.

In order to test the effects of a self-aware versus a non-self-aware conversational agent on working alliance and intervention effectiveness, two conversational agents will be experimentally manipulated, such that a "self-aware" conversational agent will present itself as a tangible and present entity by actively referring to itself ("May I help you?") in contrast to an impersonal control conversational agent which will refrain from referring to itself ("Do you need help?") and remains less tangible as an entity, fading the anthropomorphic identity of the conversational agent into the background. The overall conversational streams, message lengths, coaching elements, and schedule will be kept the same in both conditions.

\section{Research Goals and Hypotheses}

The first goal of the present study is to examine the effectiveness of $\mathrm{PEACH}$, a smartphone- and conversational agent-based coaching intervention for intentional personality change. The outcome research hypothesis is that two experimental conditions (high versus low self-aware conversational agent) will be more effective with respect to personality trait change in comparison to the two waiting list conditions. Furthermore, based on previous work on the effects of anthropomorphized computer-mediated communication on human behavior [57], the differential outcome research hypothesis is that the self-aware conversational agent will be more effective in terms of relationship-building, promoting intervention adherence and thus treatment success than the low self-aware conversational agent.

The second goal is to explore underlying processes and mechanisms that improve the outcomes of the intervention. Two approaches are used for process assessments: self-reports and smartphone sensing. Both methods include an intensive longitudinal design. This allows exploring associations between actively (self-reports) and passively (sensors) assessed intervention processes.

\section{Methods/Design \\ Design}

In this study protocol, we describe a $2 \times 2$ factorial between-subject randomized, wait-list controlled trial with intensive longitudinal methods studying the effectiveness of a 10-week smartphone- and conversational agent-based coaching intervention for intentional personality change. The effectiveness of the intervention will be compared across two dimensions: intervention (experimental versus wait-list control) and conversational agent design (high versus low self-awareness). Participants will be randomly assigned to one of four conditions: (a) experimental condition 1: conversational agent with high self-awareness, (b) experimental condition 2: conversational agent with low self-awareness, (c) wait-list condition 1: conversational agent with high self-awareness, (d) wait-list condition 2: conversational agent with low self-awareness. Participants in the wait-list control conditions will receive no intervention for the first four weeks to document the natural course of their personality change without expecting interventional effects. To monitor progress, the wait-list control groups will respond to the same weekly questionnaires during those four weeks as the subjects from the experimental conditions. Additionally, they are passively tracked by smartphone sensors. After the four weeks without any intervention, subjects of the wait-list control conditions will receive the same intervention as subjects of the experimental conditions - depending on their conversational agent embedding high or low self-awareness cues.

\section{Participants and Recruitment}

The targeted sample will include at least 900 German-speaking adults, who install the PEACH App 
on their smartphones, give informed consent, pass the screening, fill in the pre-test assessment and start with the intervention. To assure an adequate power to detect statistical significance and to demonstrate a small to medium effect of a pre-post time by group interaction we require data from 300 participants. Assuming an $\alpha$ error level of 0.05 , a statistical power $(1-\beta)$ of 0.80 , and a correlation of 0.40 between the pre- and post-measurements and 75 completers for each group, we would be able to detect a small effect of Cohen's $d=$ .22. Computing power for repeated measures, which is the case in this study, is more complex. As such, this power analysis only gives a rough idea of the effect sizes the study could reasonably detect. In a similar study [33], 67\% of participants completed the post-test survey after 6 weeks, from a cohort of 273 who started the intervention. Based on this estimate and taking the longer duration of this study into account, we expect even more attrition. Should drop-out rates be higher than expected, we may recruit additional participants to ensure sufficient statistical power. To be eligible for the study, participants must be: (1) 18 years or older; (2) able to read German; (3) not in a psychotherapeutic or psychiatric treatment; (4) owner of a smartphone (Android or iOS) with mobile internet connection; and (5) interested and motivated to participate at the intervention and to change some aspects of their personality. The focus of this intervention study is explicitly on healthy adults. Thus, adults with mental health disorders and other psychosocial problems will be excluded. Participants will complete an online eligibility screening that checks for the inclusion criteria. Excluded candidates with mental health disorders and psychosocial problems will be provided with an information and contact details of the psychological counseling service of the University of Zurich.

We will primarily use university mailings and social media advertisements for the recruitment process. Additionally, potential participants will respond to flyers or word-of-mouth recruitment. Interested people will be directed to either the website of the project (www.personalitycoach.ch) or to the Apple Store/Google Play Store to receive detailed information about the study aims, interventions, assessments, reimbursement, and data protection and download the mobile application. Participants will be automatically and randomly assigned to one of four conditions (Fig. 1). In total, the two experimental conditions will be oversampled and will include $2 / 3$ and the control condition $1 / 3$ of all participants (full randomization in all four conditions). The automated allocation and randomization procedures will be computer generated. In this way, we aim to ensure that the conditions are fully randomized with respect to the participants' baseline characteristics (allocation concealment). Because all participants will be treated using a comparable coaching intervention, participants are blinded to the two conversational agents. Spill-over effects could occur since participants might know each other and talk about the procedure of the intervention. After obtaining informed consent and passing the screening assessment, participants will be directed to the pre-test assessment. The procedure and design of the study are also depicted in Fig. 1.

Reimbursement of 25 Swiss Francs for taking part in the pre-test and follow-up assessment will be offered to study participants. Consistent with prior work (e.g. [58]), participants will be able to earn credits for active participation and by fulfilling specific tasks during the intervention such as engaging with the conversational agent (maximum 8 credits per day), experience sampling measurements ( 3 credits per measurement occasion), weekly assessments (20 credits per assessment), and photo uploads (15 credits per upload). Participants can collect 1,000 credits in total and reach bronze status with 250 credits or more, silver status with 500 credits or more, and gold status with 750 credits or more. According to their status, participants earn tickets for the lottery (bronze status $=1$ ticket, silver status $=5$ tickets, gold status $=10$ tickets). Participants can win 100 Swiss francs, 200 Swiss francs, and 300 Swiss francs in cash.

\section{Procedure}

The procedure is shown in Fig. 1. After having completed the pre-test assessment, participants get instant feedback on their actual Big Five personality trait profile (BFI-2; [59]). This feedback should help participants to choose their appropriate change goal. Participants have to pick one change profile out of nine, which fits the most to their individual change goal. Each of these nine profiles explains normal characteristics of a person with high or low levels in the corresponding Big Five personality trait. To be more precise, participants can choose between nine personality change profiles: (1) increase in conscientiousness, (2) decrease in conscientiousness, (3) increase in extraversion, (4) decrease in extraversion, (5) increase in open-mindedness, (6) decrease in open-mindedness, (7) increase in agreeableness, (8) decrease in agreeableness, and (9) decrease in negative emotionality. For ethical reasons an intervention to increase negative emotionality will not be offered. Participant then indicate the strength of their chosen change goal on an 8-point scale from $0=$ not at all to $7=$ totally and their willingness to change (i.e., goal commitment and goal attainability; [60]). Additionally, participants are asked to share a link with at least three close friends, family members and their intimate partner to obtain an observer-report on the Big Five personality traits (BFI-2-S; [61]) (Table 2). 


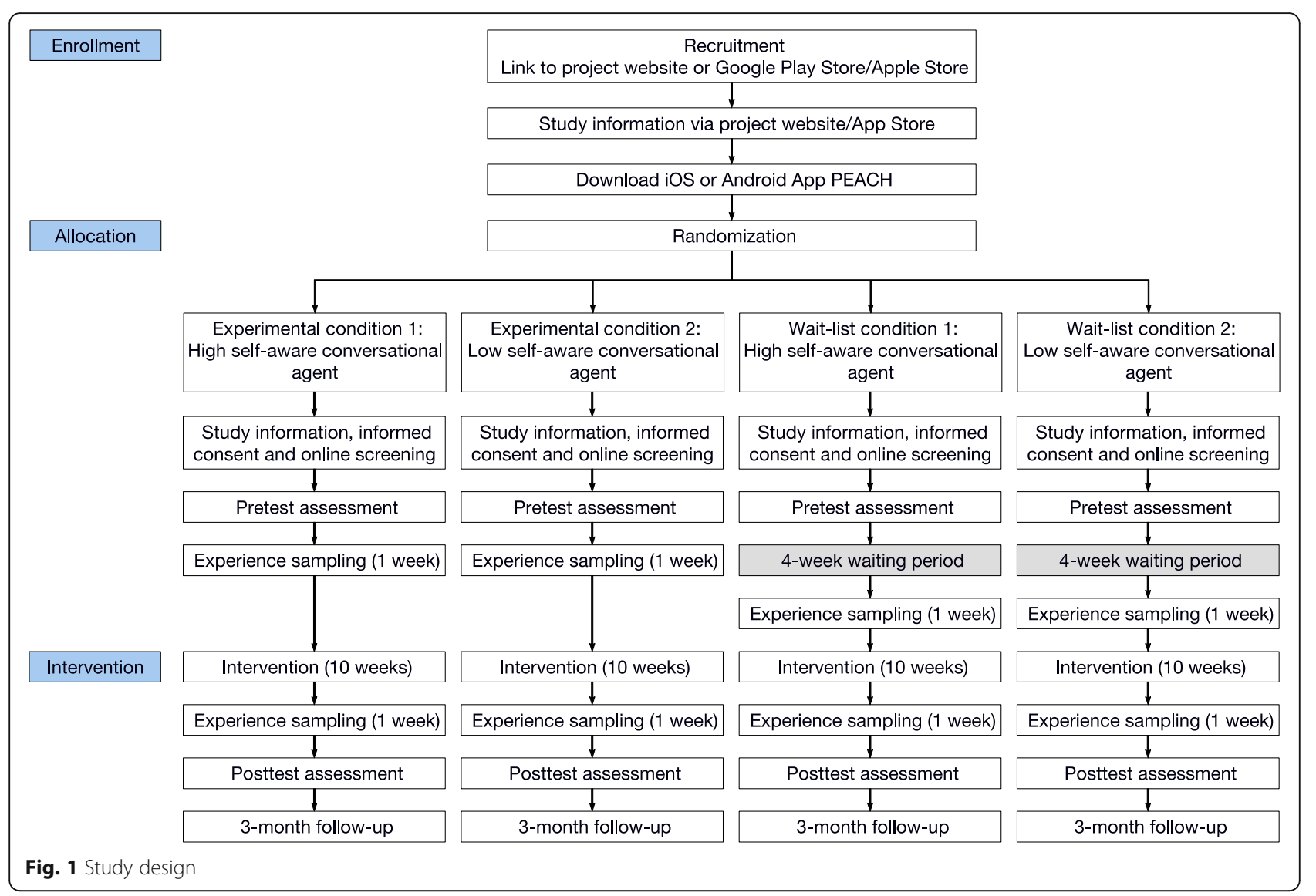

The first week of the study is an experience sampling week to measure personality manifestations in daily life (for more details, see below). The personality change intervention then lasts over 10 weeks. For each of the 10 weeks, weekly core themes will be provided (Table 1). Moreover, six different types of micro-interventions will be used in the intervention (see below). All participants are actively involved in two daily dialogues with the conversational agent. In the morning at an individually preferred time participants receive the first message for the morning dialogue and in the evening again at an individually preferred time participants receive the first message for the evening dialogue. Participants have the opportunity to read the dialogue until it is time for the next dialogue. A conversational agent will be used to remind participants to complete questionnaires, to guide them through micro-interventions, to promote commitment, to motivate participants, and to support the change process (Fig. 2). During these conversations, a combination of pre-defined answers and free-text input is used to constrain the dialog along pre-defined counselling paths and to give participants autonomy where needed (e.g., for the definition of implementation intentions in the if-then form). If participants do not actively use the PEACH app over three days, the study team will contact them via the "Support-Team Channel" (Fig. 2) and ask them whether there occurred any problems or whether they have any unanswered questions to promote adherence. After the intervention, there is a second experience sampling week and then participants are asked to answer the post-test assessment and the three-month follow-up assessment (Fig. 1). Moreover, participants were asked at post-test and follow-up assessment to share a link with their close friends, family members or intimate partners, who already provided their observer-reports at pre-test assessment, to obtain a second and third observer-report on the Big Five personality traits (BFI-S-S; [61]).

\section{Weekly Core Themes and Micro-Interventions}

The structure of the PEACH intervention includes (a) weekly core themes with specific micro-interventions and (b) micro-interventions that are not directly related to the weekly core themes. The weekly core themes and the micro-interventions that were used every day for 10 weeks are shown in Table 1 . In the following, we briefly discuss the six types of micro-interventions that were used in PEACH: (1) individualized implementation 
Table 1 Schedule of weekly core themes and micro-interventions

\begin{tabular}{|c|c|c|c|c|c|c|}
\hline Week & $\begin{array}{l}\text { Weekly core } \\
\text { theme (Source) }\end{array}$ & Brief description & $\begin{array}{l}\text { Individualized } \\
\text { implementation } \\
\text { intentionc }^{c}\end{array}$ & Psycho-education ${ }^{\mathrm{b}}$ & $\begin{array}{l}\text { Behavioral } \\
\text { activation } \\
\text { tasks }{ }^{c}\end{array}$ & $\begin{array}{l}\text { Individualized } \\
\text { progress } \\
\text { feedback }\end{array}$ \\
\hline 1 & $\begin{array}{l}\text { Organizing a } \\
\text { change team } \\
{[27]}\end{array}$ & $\begin{array}{l}\text { Participants are asked to inform 1-3 sig- } \\
\text { nificant others such as friends or family } \\
\text { members to talk with them about their } \\
\text { change goals, the coaching intervention } \\
\text { itself and to keep them updated during } \\
\text { the intervention. }\end{array}$ & $\begin{array}{l}\text { Implementation } \\
\text { intention } 1\end{array}$ & $\begin{array}{l}\text { Daily film clip or } \\
\text { scientific input }\end{array}$ & $\begin{array}{l}\text { Behavioral } \\
\text { activation } \\
\text { task } 1\end{array}$ & Dashboard \\
\hline 2 & $\begin{array}{l}\text { Learning from } \\
\text { experiences by } \\
\text { systematic } \\
\text { reflection }^{\mathrm{b}}[17]\end{array}$ & $\begin{array}{l}\text { People are asked to analyze their own } \\
\text { behavior and advance explanations for } \\
\text { the resulting success or failure to learn } \\
\text { from both. Questions that prompt self- } \\
\text { explanations include: "How did you con- } \\
\text { tribute to the performance?" or "How ef- } \\
\text { fective were you in the experience". Then } \\
\text { participants are confronted with questions } \\
\text { such as "Consider a different approach } \\
\text { that could have been taken." And finally } \\
\text { they should ask themselves: "What } \\
\text { worked and what did not work? How will } \\
\text { you behave in the future?" }\end{array}$ & $\begin{array}{l}\text { Implementation } \\
\text { intention } 2\end{array}$ & $\begin{array}{l}\text { Daily film clip or } \\
\text { scientific input }\end{array}$ & $\begin{array}{l}\text { Behavioral } \\
\text { activation } \\
\text { task } 2\end{array}$ & Dashboard \\
\hline 3 & $\begin{array}{l}\text { Identifying } \\
\text { situational/ } \\
\text { contextual } \text { triggers }^{\mathrm{b}}[23]\end{array}$ & $\begin{array}{l}\text { Participants learn how to identify } \\
\text { situational and contextual triggers (e.g., } \\
\text { people, places, time in the day) that help } \\
\text { or hinder them to show their desired } \\
\text { behavior. }\end{array}$ & $\begin{array}{l}\text { Implementation } \\
\text { intention } 3\end{array}$ & $\begin{array}{l}\text { Daily film clip or } \\
\text { scientific input }\end{array}$ & $\begin{array}{l}\text { Behavioral } \\
\text { activation } \\
\text { task } 3\end{array}$ & Dashboard \\
\hline 4 & $\begin{array}{l}\text { Thinking and } \\
\text { writing about } \\
\text { the pro's and } \\
\text { con's of } \\
\text { change }^{\text {a }}[15]\end{array}$ & $\begin{array}{l}\text { Participants think about advantages and } \\
\text { disadvantages of changing in the desired } \\
\text { direction and of staying the same. This } \\
\text { might eventually also enhance individual } \\
\text { change motivation. }\end{array}$ & $\begin{array}{l}\text { Implementation } \\
\text { intention } 4\end{array}$ & $\begin{array}{l}\text { Daily film clip or } \\
\text { scientific input }\end{array}$ & $\begin{array}{l}\text { Behavioral } \\
\text { activation } \\
\text { task } 4\end{array}$ & Dashboard \\
\hline 5 & $\begin{array}{l}\text { Learning from } \\
\text { others by } \\
\text { observational } \\
\text { learning } \\
{[20,21]}\end{array}$ & $\begin{array}{l}\text { Participants should look out for people in } \\
\text { their environment, who already show } \\
\text { their desired behavior. They analyze what } \\
\text { these people are doing differently and try } \\
\text { to model this behavior. }\end{array}$ & $\begin{array}{l}\text { Implementation } \\
\text { intention } 5\end{array}$ & $\begin{array}{l}\text { Daily film clip or } \\
\text { scientific input }\end{array}$ & $\begin{array}{l}\text { Behavioral } \\
\text { activation } \\
\text { task } 5\end{array}$ & Dashboard \\
\hline 6 & $\begin{array}{l}\text { Self-reflection } \\
\text { by means of } \\
\text { introspection }^{\text {b }} \\
{[21,22]}\end{array}$ & $\begin{array}{l}\text { Participants should watch their own } \\
\text { thoughts and feelings when they are able } \\
\text { to show their desired behavior and } \\
\text { thoughts and feelings when they are not } \\
\text { able to show the desired behavior. }\end{array}$ & $\begin{array}{l}\text { Implementation } \\
\text { intention } 6\end{array}$ & $\begin{array}{l}\text { Daily film clip or } \\
\text { scientific input }\end{array}$ & $\begin{array}{l}\text { Behavioral } \\
\text { activation } \\
\text { task } 6\end{array}$ & Dashboard \\
\hline 7 & $\begin{array}{l}\text { Keeping a diary } \\
\text { of strengths } \\
\text { and resources }{ }^{d} \\
{[28]}\end{array}$ & $\begin{array}{l}\text { Participants are asked to think about what } \\
\text { they are grateful in life and about their } \\
\text { personal strengths. }\end{array}$ & $\begin{array}{l}\text { Implementation } \\
\text { intention } 7\end{array}$ & $\begin{array}{l}\text { Daily film clip or } \\
\text { scientific input }\end{array}$ & $\begin{array}{l}\text { Behavioral } \\
\text { activation } \\
\text { task } 7\end{array}$ & Dashboard \\
\hline 8 & $\begin{array}{l}\text { Reflecting } \\
\text { about strengths } \\
\text { and resources } \\
\text { using the tree } \\
\text { of resources } \\
{[29]}\end{array}$ & $\begin{array}{l}\text { Participants write down individual } \\
\text { resources inside their tree of resources in } \\
\text { order to visualize and reflect about } \\
\text { personal strengths and positive aspects } \\
\text { of life. }\end{array}$ & $\begin{array}{l}\text { Implementation } \\
\text { intention } 8\end{array}$ & $\begin{array}{l}\text { Daily film clip or } \\
\text { scientific input }\end{array}$ & $\begin{array}{l}\text { Behavioral } \\
\text { activation } \\
\text { task } 8\end{array}$ & Dashboard \\
\hline 9 & $\begin{array}{l}\text { Thinking about } \\
\text { the desired } \\
\text { personality } \\
\text { using miracle } \\
\text { questions }^{a}[16]\end{array}$ & $\begin{array}{l}\text { Miracle questions are thought } \\
\text { experiments, which ask people to } \\
\text { imagine their desired personality, their } \\
\text { desired future and specific plans and their } \\
\text { priorities for the } \\
\text { next five years. }\end{array}$ & $\begin{array}{l}\text { Implementation } \\
\text { intention } 9\end{array}$ & $\begin{array}{l}\text { Daily film clip or } \\
\text { scientific input }\end{array}$ & $\begin{array}{l}\text { Behavioral } \\
\text { activation } \\
\text { task } 9\end{array}$ & Dashboard \\
\hline 10 & $\begin{array}{l}\text { Looking } \\
\text { forward and } \\
\text { thinking about } \\
\text { the future }{ }^{d}[30]\end{array}$ & $\begin{array}{l}\text { Participants should think about } \\
\text { future plans, dreams, hopes, } \\
\text { and poss }\end{array}$ & $\begin{array}{l}\text { Implementation } \\
\text { intention } 10\end{array}$ & $\begin{array}{l}\text { Daily film clip or } \\
\text { scientific input }\end{array}$ & $\begin{array}{l}\text { Behavioral } \\
\text { activation } \\
\text { task } 10\end{array}$ & Dashboard \\
\hline
\end{tabular}

Note. ${ }^{a}$ Actuating discrepancy awareness; ${ }^{b}$ targeting thoughts and feelings to realize insight; ${ }^{c}$ targeting behaviors to realize practice; ${ }^{d}$ activate strengths and resources to realize strengths-orientation; since these general change mechanisms are overlapping in content, weekly core themes and micro-interventions might fit to more than just one general change mechanism 


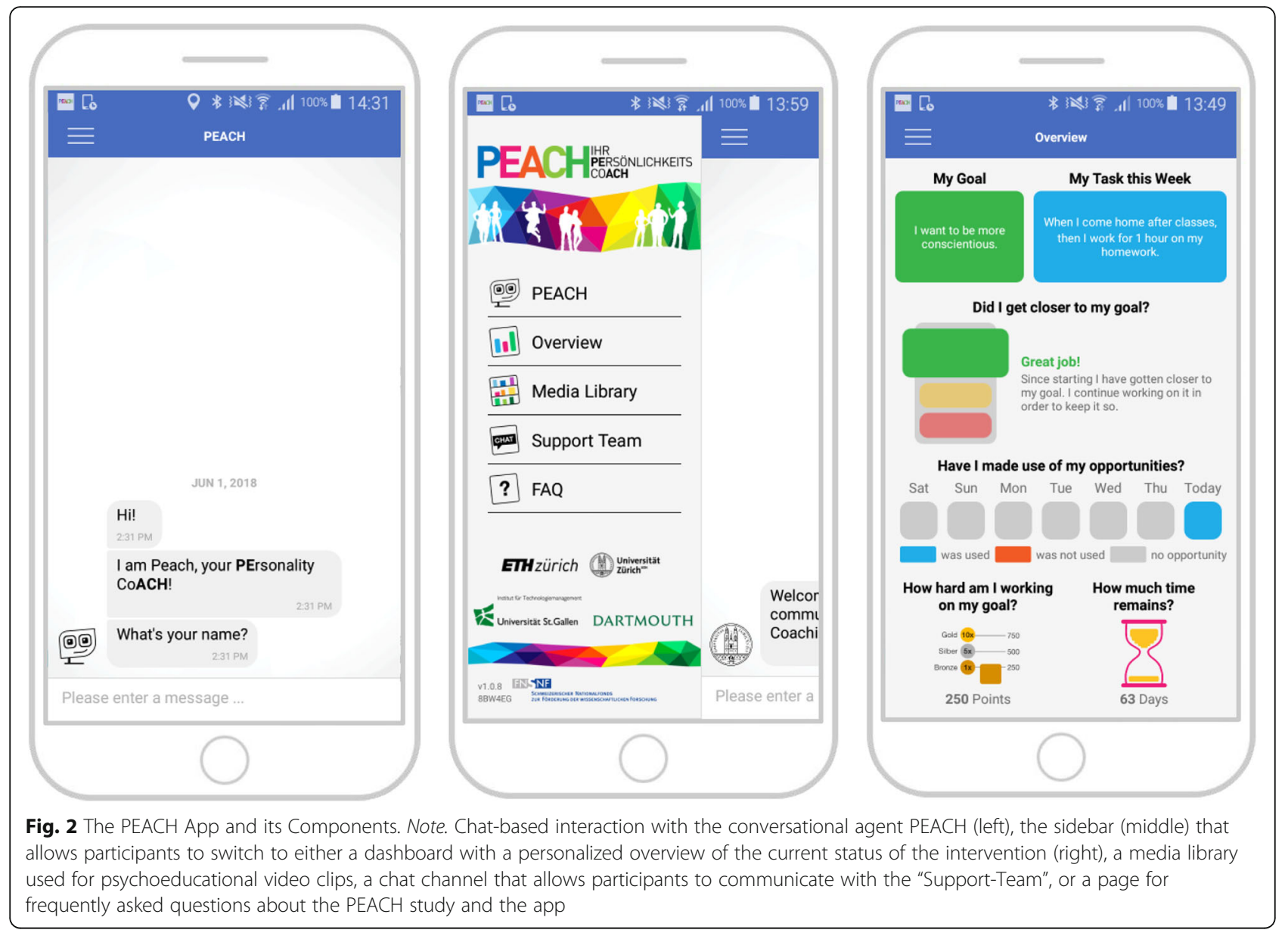

intention, (2) psychoeducation, (3) behavioral activation, (4) self-reflection, (5) resource activation, and (6) individualized progress feedback. The included micro-interventions were selected to target and to activate the general (common) change mechanisms in order to maximize the effects of the intervention [7].

\section{Individualized implementation intentions}

An implementation intention is a self-regulatory strategy in the form of an "if-then plan" that can lead to better goal attainment $[5,24]$. This micro-intervention targets the general change mechanism targeting behaviors to realize practice. Participants generate one individual and specific implementation intention based on suggested behavioral activation task every Sunday. This individually built implementation intention should be implemented in daily life during the following week as often as possible. Examples for implementation intentions are: "If I have to work concentrated, then I switch into flight mode" (Productivity, Conscientiousness), "If I have no meetings before 1:00 p. $\mathrm{m}$, then I will go to the gym." (Productivity, Conscientiousness) or "If I see something beautiful, then I will take a photo." (Aesthetic Sensitivity, Open-Mindedness).

\section{Psychoeducation}

Psychoeducation fosters knowledge transfer about personality dispositions, personality change and its outcomes. This micro-intervention operationalizes the general change mechanism targeting thoughts and feelings to realize insight. In the present coaching intervention, participants receive every morning either a short film clip or a message with scientific "food for thought". In total, we developed 36 film clips (11 film clips providing information about personality dispositions and personality change in general and 5 film clips for each participant fitting to the chosen change goal and its outcomes) and 104 scientific messages (34 providing input about personality dispositions and personality change in general and 10 messages for each participant fitting to the chosen change goal). Film clips provide worst- and best-case scenarios and scientific facts about the advantages of achieving the desired change. These interactive elements should also promote motivation and adherence among participants.

\section{Behavioral activation tasks}

Behavioral activation directly changes actual behavior and reinforces new behavior. This micro-intervention 
operationalizes the general change mechanism targeting behaviors to realize practice. In the present coaching intervention, participants receive three new suggestions of behavioral activation tasks every Sunday, which fit to their chosen change goal $[25,26]$. Out of these three suggestions, participants select one behavioral activation task with the goal to implement the task in their daily routine during the following week. Examples for behavioral activation tasks are: "Don't procrastinate and do things right away." (Productiveness, Conscientiousness), "Tidy up a part of your flat every day." (Organization, Conscientiousness) or "Take a photo of something beautiful every day." (Aesthetic Sensitivity, Open-Mindedness). In total, we developed 12 behavioral activation tasks for each of the nine Big Five personality trait profiles (108 behavioral activation tasks in total) (cf. [59]).

\section{Self-reflection}

Self-reflection is a tool to exercise introspection, learn from experiences including successes and failures. This micro-intervention is included to target the general change mechanism targeting thoughts and feelings to realize insight. Different tools to exercise self-reflection are included in the weekly core themes, which change every week to enhance adherence and are embedded in every dialogue in the evening (Table 1).

\section{Resource activation}

Resource activation capitalizes on individual and interpersonal strengths and resources. This micro-intervention is included to target the general change mechanism activating strengths and resources to realize strengths-orientation. Tools including resource activation are also included in the weekly core themes, which change every week (Table 1).

\section{Individualized progress feedback}

Individually tailored progress feedback is one of the most commonly used change techniques in smartphone-based health interventions [13] that helps people to focus on their discrepancy awareness. This micro-intervention targets the general change mechanism actuating discrepancy awareness. Participants constantly receive individualized graphical feedback on the dashboard of the PEACH app (Fig. 2). For instance, they can check whether they are already approaching their change goal compared to the beginning of the intervention. Additionally, they get feedback about how often they had opportunities to show their weekly implementation intention and how often they actually implemented it during the last seven days. Furthermore, they can check their momentary status (bronze, silver or gold status) and see the credits they have already earned during the intervention (Fig. 2).

\section{Assessment Strategy}

The assessment strategy includes (1) a screening assessment (self-reported), (2) an outcome assessment (self-reported and observer-reported), (3) a process assessment (self-reported), and (4) smartphone sensing. An overview is shown in Table 2. These different types of assessments will be further elaborated in the following.

\section{Screening assessment}

During the onboarding process (Fig. 1), participants will respond to two screening questionnaires to check for eligibility. Participants are directed from the PEACH app to the online survey tool (limesurvey.org), so that they can answer the screening questionnaires on their smartphone. Short forms of the Symptom-Check List (SCL-K11; [62]) and Depression Scale (ADS-K; [63]) will be used to assess mental health disorders and other psychosocial problems (Table 2). Individuals with scores above the cut-off value in the SCL-K11 $(\geq 14)$ and above the cut-off value in the ADS-K $(\geq 19)$ will be excluded and are provided with information and contact details of the psychological counseling service of the University of Zurich.

\section{Outcome assessment}

Self-reports The self-reports include a pre-test, a post-test and a three-month follow-up assessment. Pre-test assessment will take place before the intervention, post-test assessment after the intervention and the follow-up assessment three months after the end of the intervention to check whether personality changes could be maintained over a longer period of time or revert over time. At all points of measurement participants will be automatically directed from the PEACH app to the online survey tool (limesurvey.org) to answer all questionnaires on the smartphone (Fig. 3). The main outcome assessment includes the Big Five Inventory 2 (BFI-2; [59]) to assess the Big Five personality traits and trait-related facets. Further outcome variables and control variables are willingness to change [60], implicit theory of personality [64], satisfaction with life (SWLS; [65]), satisfaction with life domains [2], and self-esteem (RSES; [66]) (Table 2).

Main outcomes regarding the relationship building process with the conversational agent include the following: Working alliance will be assessed using an adapted short-version [67] of the Working Alliance Inventory (WAI-SR) [52] based on Kiluk et al.'s [68] work, who adapted the complete WAI to measure working alliance with a technology-based intervention (WAI-Tech). To further understand the perception of the conversational agents, the Perception of Robots scale [69] and trust measures [70] to assess trust development mechanisms will be included. Interpersonal closeness will be measured with the Inclusion-of-the-Other-in-the-Self (IOS) 
Table 2 Measures

Screening Pre-Test Experience $\frac{\text { Intervention }}{\text { Daily Weekly }}$ Post-Test Follow-up Evaluation
Sampling

Screening

Symptom-Check List (SCL-K11; [62])

Depression Scale (ADS-K; [63])

Demographics

Main Outcome Assessment - Self report

Big Five Personality Inventory (BFI-2; [59])

Main Outcome Assessment - Observer Report

Big Five Personality Inventory (BFI-2-S; [61])

Process Assessment - Self report

Big Five Personality Inventory 2 (BFl-2-S; [61])

Big Five personality states

Affect (PAM; [75])

Information about current environment

Stress level

Realization of implementation intention

Opportunities for realization of implementation intention

Strength of change goal

Subjective perception of change

Learning experience

Inclusion-of-the-Other-in-the-Self [71]

Working Alliance Inventory (WAI-SR, [67])

Perception of Robots [69]

Trust [70]

Further Outcome \& Control variables - Observer report

Demographics

Type and closeness of relationship

Time spent with target person

Further Outcome \& Control variables - Self report

Willingness to change [60]

Implicit theory of personality [64]

Satisfaction with life domains [2]

Satisfaction with Life Scale [65]

Rosenberg Self-Esteem Scale (RSES; [66])

Engagement in self reflection

Engagement in practice

Feedback on components of the coaching

Technology acceptance scales [74]

Internet users' privacy concerns [89]

Technical anxiety [90]

Manipulation check items

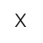

$\begin{array}{ll}x & x \\ x & x \\ x & \\ x & x \\ & x\end{array}$

$\begin{array}{lll}x & x & x \\ x & x & x \\ x & & \\ \text { biweekly } & x & \\ \text { biweekly } & x & \\ & x & \\ \text { four-weekly } & x\end{array}$




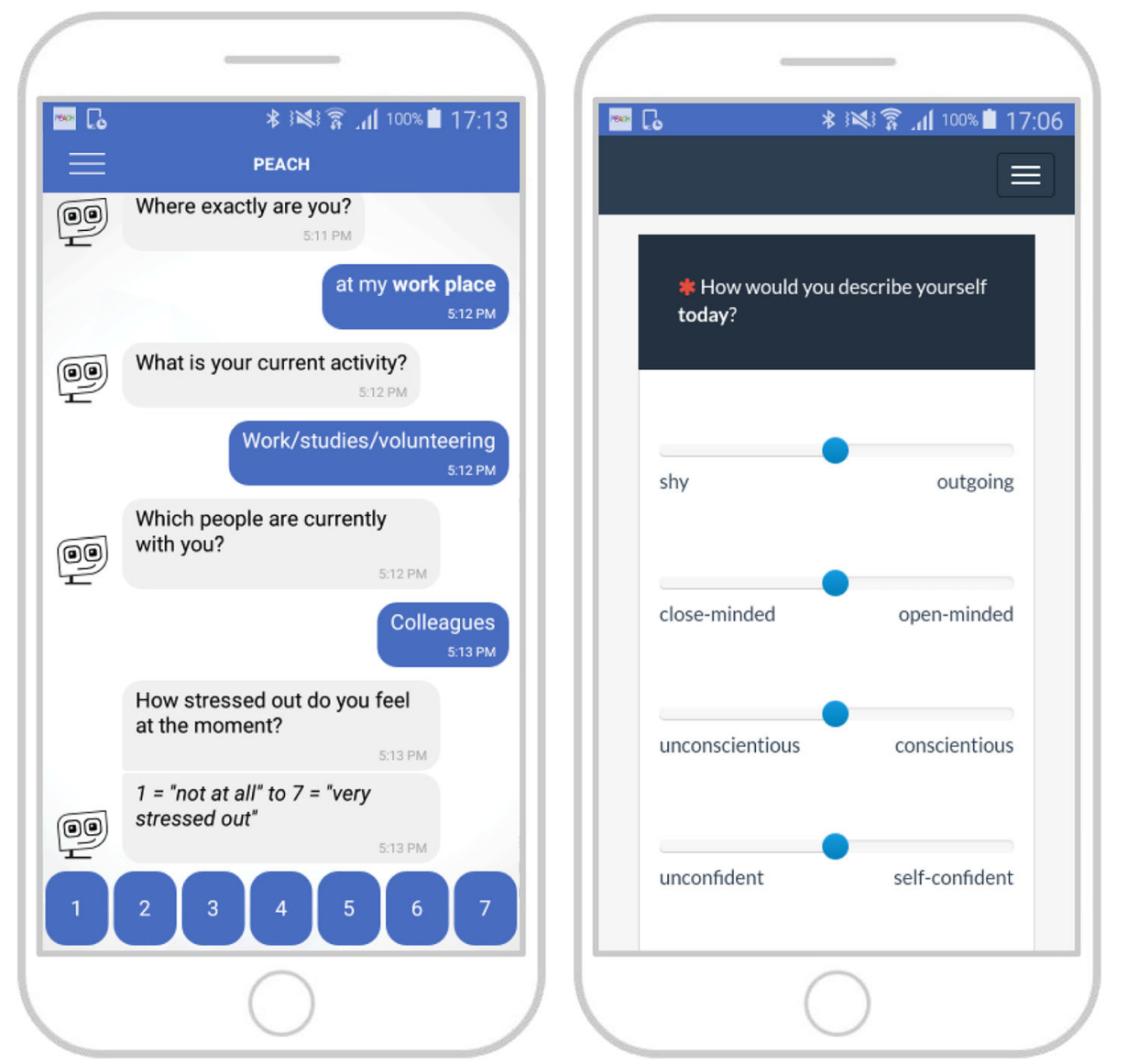

Fig. 3 User interface for survey data collection. Note. Experience sampling assessment with self-reports (left) and daily diary assessment of the Big Five personality states (right) using bipolar adjective items (ad hoc translation from German)

scale [71], an established and reliable instrument to measure perceived closeness of a relationship [72]. Manipulation checks for perceived self-awareness of the conversational agents [73] will be conducted every four weeks to confirm that the manipulation had been scripted thoroughly throughout the 10-weeks of intervention.

Overall satisfaction with the app, ease of use, perceived enjoyment, and perceived usefulness will be measured after the first week and at the end of the intervention [74] to identify differences in the perception of the conversational agent due to differences in the usability of the app. Moreover, we are interested in qualitative feedback of users at the beginning of the interaction with the conversational agents (first impression) and at the end of the intervention to eventually improve the interaction with and perception of the conversational agents.

Observer reports In addition to self-reports, observer-reports by close others will be assessed. At the beginning of the study, participants will be asked to share a link to the online observer-report questionnaires with at least three close friends, family members or their intimate partner. Observer-reports include the Big Five personality traits (BFI-2-S; [61]), type and closeness of the relationship and time spent with the target person. Observer-reports will be assessed at pre-test, post-test and follow-up assessment (Table 2).

\section{Process assessment}

Experience sampling with self-reports One week before the intervention and one week after the intervention (Fig. 1), there will be an experience sampling with self-reports including four assessments per day (Fig. 3) at random times once in each of four predefined time windows: 9:30 a. m. 11:30 a. m., 12:30 p. m. - 14:30 p. m., 15:30 p. m. - 17:30 p. m., 18:30 p. m. - 20:30 p. m. Participants will be asked to behave the first week as normal as possible and not to change anything in their behavior in order to measure their baseline behavioral signatures. After the intervention, participants are asked to answer the same experience sampling questions again during one week. This allows to check for changes in the behavioral signatures as a result of the intervention. Experience sampling assessments include the photographic 
affect meter (PAM; [75]) to assess momentary affect, five bipolar adjective items to assess the Big Five personality states (presentation in a random order), a few questions about the current location (e.g., indoors versus outdoors), activity, and social environment (e.g. alone versus with other people) at the moment, and a single item to measure momentary stress.

Daily diary and weekly self-report assessments During the intervention, there will be daily diary and weekly measurements to assess individual change progress. The photographic affect meter (PAM; [75]) and ten bipolar adjective items to assess Big Five personality states will be used on a daily basis every evening. Additionally, participants are asked every evening whether they had opportunities to show their individual implementation intention and whether they could perform their implementation intention. There will be a weekly assessment every Sunday including a short version of the BFI-2 (BFI-2-S; [61]) (Table 2).

\section{Smartphone sensing}

Smartphone applications can get access to data from sensors and usage logs (e.g. location, surrounding devices via Bluetooth, logs of application usage and phone calls), which allow objective measurement of behavior, and inferences about users' personality [76, 77]. Using this data, it may also be possible to detect changes in personality over short periods of time. If the application detects changes in behavior that are consistent with desired changes in personality and associated with the use of the PEACH app, this would constitute complementary evidence for PEACH's effectiveness.

\section{Technological Background of the Intervention}

The smartphone-based coaching intervention is based on the MobileCoach (www.mobile-coach.eu). The MobileCoach is an open source platform for the design, delivery and evaluation of scalable smartphone-based interventions $[40,43,78]$. It is available via the research and industry-friendly Apache 2 license and follows a client-server model. The rule-based intervention logic and messages are defined by intervention authors on the server. MobileCoach then acts as a conversational agent and uses these rules to send out the intervention messages to client applications on mobile devices. MobileCoach also allows to react to answers given by intervention participants and can deliver these interventions via the widely available short message service (e.g., to lower the threshold for participation and to maximize the reach of an intervention) and/or via dedicated mobile messaging apps for Apple's iOS and Google's Android platform. The mobile messaging apps allow not only to fully customize the user experience to a particular target group (e.g., the look and feel of the app with various conversational agents) but also to use sensor data from smartphones and/or other connected devices to deliver just in time adaptive interventions based on end users' states of receptivity and vulnerability $[79,80]$.

Previous studies have demonstrated the effectiveness and reach of MobileCoach-based interventions with regard to problem drinking in adolescents [58] and perceived ease of use, enjoyment, therapy adherence and scalability in a childhood obesity intervention [40, 43]. In addition to delivering interventions, MobileCoach is also used for the collection of intensive longitudinal data in situ (e.g., for ecological momentary assessments), for example in a clinical trial on stress disorders.

In the PEACH study, the iOS and Android apps of MobileCoach are used to guide participants through the micro-interventions, providing motivation, promoting commitment, and reminding them to complete questionnaires. During these conversations, a combination of pre-defined answers and free-text input is used to constrain the dialog along pre-defined counselling paths and to give the participant autonomy where needed (e.g., for the definition of implementation intentions in the if-then form). With a swipe-to-the-right gesture or via a menu button, participants can open the sidebar of the PEACH app (Figure 2) from which they can navigate to (a) their personal dashboard, (b) a media library used for psychoeducation video clips which are unlocked along the intervention path, (c) a second chat channel "Support-Team" for a traditional WhatsApp like communication with the study team (e.g., to clarify technical questions and comments), or (d) to a page for frequently asked questions about the PEACH study and the PEACH app. From the sidebar, participants can also navigate back to the chat channel with the conversational agent and to the dashboard (Fig. 2). The dashboard gives an overview of the self-selected personality change goal and the weekly individual implementation intention. It also provides a traffic light, whether an individual was able to get closer to its intended personality change goal (green light), further away from it (red light) or whether there is no change in any direction (yellow light). For this comparison, participants self-reported ratings of the Big Five personality states (bipolar adjective scales) for the last seven days will be compared to his/her ratings of the Big Five personality states of the first week of the intervention. The traffic light changes to green or red when the averaged delta of scores between the last and the first week is more than half a standard deviation. The rationale of using a time window of seven days was to account for natural variance in daily ratings of study participants. The dashboard also visualizes whether and on which day participants had 
opportunities to pursue and in fact realize their individual implementation intention during the last seven days. Eventually, the personal dashboard illustrates their latest credit score and the remaining time of the intervention program.

\section{Data Analyses}

Longitudinal multilevel modeling (MLM) and structural equation modeling (SEM) will be used to analyze the (intensive) longitudinal, nested data structure and change over time [81-84]. Both data-analytic methods are specifically suitable to model change explicitly as a function of time and can be used to formulate equivalent models, providing identical estimates for the collected data. Separate models will be analyzed including the outcome assessments at pre-, post- and follow-up (self-reports and observer-reports), daily diary assessments, and weekly self-report assessments. Predictor/control variables will be added to the models to examine how individual growth will be moderated by variables such as intervention condition, change goal or willingness to change. The statistical modeling programs Mplus [85], and updated R packages (R Core Team, Vienna Austria) will be used to estimate the growth curve models.

\section{Discussion}

This study is the first one testing the effectiveness of a smartphone- and conversational agent-based theory-driven intervention for intended personality change to support people who want to change self-selected personality traits. Understanding short-term changeability of personality traits in daily life and examining whether potential intentional personality trait changes can be maintained or rather revert over time is a key goal in the research fields of personality development and personality dynamics and complements previous longstanding work on long-term changes of personality traits across the lifespan. This is particularly important because personality changes can have a powerful impact on people's lives. For example, becoming more conscientious over longer time periods is related to more health-related behaviors and ultimately to better health and well-being [86, 87]. Intended personality changes such as decreases in neuroticism may also reduce economic costs [88].

The study will not only advance our understanding of the short-term changeability of personality traits and intended efforts to change them, but also increase our knowledge of underlying short-term processes and dynamics of change. Furthermore, the study contributes to the understanding of the design of text-based conversational agents and the role of conversational agents in supporting and coaching individuals to reach their individual change goals. This is particularly interesting since empirical evidence of text-based conversational agents on the effectiveness of smartphone-based interventions is still sparse. The application of the talk-and-tools paradigm used in the PEACH mobile app can not only complement and extend existing face-to-face counseling sessions to the everyday life of individuals, but can also provide new means to offer smartphone-based coaching interventions in a scalable fashion where a personal coaching approach is not feasible due to limited reach, personnel or budget.

Given that the intervention approach of the PEACH mobile app proves effective, it could be easily implemented in various non-clinical settings such as counseling/mentoring (e.g., individual change processes) or coaching (e.g., personality related aspects in diet, fitness, health and well-being) and could reach large numbers of people due to its low-threshold character.

\section{Funding}

Swiss National Science Foundation (SNSF), Award Number: 162724, Recipients: Mathias Allemand (PI), Mike Martin, Christoph Flückiger, Elgar Fleisch

\section{Availability of data and materials}

Not applicable to this article as the study is ongoing and data are currently being collected. The Swiss National Science Foundation (SNSF) expects that data generated by this project are publicly accessible in digital databases provided there are no legal, ethical, copyright or other issues. An overview of the output data is available at: http://p3.snf.ch/Project-162724.

\section{Authors' contributions \\ All authors conceived and designed the study and were involved in conceptualizing and writing up the present manuscript. MS, MN, TK and DR drafted the manuscript. CF and MA provided input on drafts of the manuscript and made revisions. All authors read and approved the final manuscript.}

\section{Ethics approval and consent to participate}

This study protocol was approved by the Ethics Committee of the Philosophical Faculty of the University of Zurich, Switzerland (Number of Approval: 17.8.4, Date of Approval: $31^{\text {st }}$ August, 2017). All participants receive written information about the research project, benefits and risks of participation. They are informed that they can withdraw from the study at any time. Informed consent is obtained prior to assessment and intervention.

Consent for publication

Not applicable.

\section{Competing interests}

The authors declare that there are no competing financial interests.

\section{Publisher's Note}

Springer Nature remains neutral with regard to jurisdictional claims in published maps and institutional affiliations.

\section{Author details}

${ }^{1}$ Department of Psychology and URPP Dynamics of Healthy Aging, University of Zurich, Andreasstrasse 15, 8050 Zürich, Switzerland. ${ }^{2}$ Technology Marketing, ETH Zurich, Weinbergstrasse 56/58, 8092 Zürich, Switzerland. ${ }^{3}$ Center for Digital Health Interventions, Information Management, ETH Zurich, Weinbergstrasse 56/58, 8092 Zürich, Switzerland. ${ }^{4}$ Center for Digital Health Interventions, Institute of Technology Management, University of St.Gallen (ITEM-HSG), Dufourstrasse 40a, St.Gallen, Switzerland. ${ }^{5}$ Department of Psychology, University of Zurich, Binzmühlestrasse 14/04, 8050 Zürich, Switzerland. 
Received: 3 July 2018 Accepted: 28 August 2018 Published online: 04 September 2018

\section{References}

1. Allan JA, Leeson P, Martin LS. Who wants to change their personality and what do they want to change? Int Coach Psychol Rev. 2014;9(1):8-21.

2. Hudson NW, Roberts BW. Goals to change personality traits: concurrent links between personality traits, daily behavior, and goals to change oneself. J Res Pers. 2014; https://doi.org/10.1016/j.jrp.2014.08.008.

3. Hudson NW, Fraley RC. Do people's desires to change their personality traits vary with age? An examination of trait change goals across adulthood. Soc Psychol Personal Sci. 2016; https://doi.org/10.1177/1948550616657598.

4. Martin LS, Oades LG, Caputi P. A step-wise process of intentional personality change coaching. Int Coach Psychol Rev. 2014;9(2):181-95.

5. Hudson NW, Fraley RC. Volitional personality trait change: can people choose to change their personality traits? J Pers Soc Psychol. 2015; https:// doi.org/10.1037/pspp0000021.

6. Hudson NW, Fraley RC. Changing for the better? Longitudinal associations between volitional personality change and psychological well-being. Pers Soc Psychol Bull. 2016; https://doi.org/10.1177/0146167216637840.

7. Allemand M, Flückiger C. Changing personality traits: some considerations from psychotherapy process-outcome research for intervention efforts on intentional personality change. J Psychother Integr. 2017; https://doi.org/10. 1037/int0000094.

8. Grawe K. Psychological psychotherapy. Cambridge, MA: Hogrefe \& Huber; 2004

9. Grawe K, Donati R, Bernauer F. Psychotherapie im Wandel: Von der Konfession zur Profession. Göttingen: Hogrefe; 1994.

10. Lambert MJ. Bergin and Garfield's handbook of psychotherapy and behavior change. Hoboken, NJ: Wiley; 2013.

11. Norcross JC, Lambert MJ. Psychotherapy relationships that work. 3rd ed. New York: Oxford University Press; 2018.

12. Flückiger C, Grosse Holtforth MG, Znoj HJ, Caspar F, Wampold BE. Is the relation between early post-session reports and treatment outcome an epiphenomenon of intake distress and early response? A multi-predictor analysis in outpatient psychotherapy. Psychother Res. 2013; https://doi.org/ 10.1080/10503307.2012.693773.

13. Free C, Phillips G, Galli L, Watson L, Felix L, Edwards P, et al. The effectiveness of mobile-health technology-based health behaviour change or disease management interventions for health care consumers: a systematic review. PLoS Med. 2013; https://doi.org/10.1371/journal.pmed. 1001362.

14. Martin LS, Oades LG, Caputi P. Intentional personality change coaching: a randomised controlled trial of participant selected personality facet change using the five-factor model of personality. Int Coach Psychol Rev. 2014;9(2): 196-209.

15. Miller WR, Rollnick S. Meeting in the middle: motivational interviewing and self-determination theory. Int J Behav Nutr Phys Act. 2012; https://doi.org/ 10.1186/1479-5868-9-25

16. De Shazer S. Clues: investigating solutions in brief therapy. New York: WW Norton \& Company, Inc; 1988.

17. Ellis S, Carette B, Anseel F, Lievens F. Systematic reflection: implications for learning from failures and successes. Curr Dir Psychol Sci. 2014; https://doi. org/10.1177/0963721413504106.

18. Dweck CS. Can personality be changed? The role of beliefs in personality and change. Curr Dir Psychol Sci. 2008; https://doi.org/10.1111/j.1467-8721. 2008.00612.x.

19. Donker T, Griffiths KM, Cuijpers P, Christensen H. Psychoeducation for depression, anxiety and psychological distress: a meta-analysis. BMC Med. 2009; https://doi.org/10.1186/1741-7015-7-79.

20. Bandura A. Social foundations of thought and action: a social cognitive theory. Englewood Cliffs: Prentice-Hall; 1986

21. Caspi A, Roberts BW. Personality development across the life course: the argument for change and continuity. Psychol Inq. 2001; https://doi.org/10. 1207/S15327965PLI1202 01.

22. Bem DJ. Self-perception theory. In: Berkowitz L, editor. Advances in experimental social psychology. New York: Academic Press; 1972. p. 1-62.

23. Roberts BW, Wood D, Caspi A. The development of personality traits in adulthood. In: John OP, Robins RW, Pervin LA, editors. Handbook of personality: theory and research. New York: Guilford Press; 2008. p. 375-98.
24. Gollwitzer PM, Brandstätter V. Implementation intentions and effective goal pursuit. J Pers Soc Psychol. 1997; https://doi.org/10.1037/0022-3514.73.1.186.

25. Dimidjian S, MJr B. Martell C. Muñoz RF: Lewinsohn PM. The origins and current status of behavioral activation treatments for depression. Annu Rev Clin Psychol; 2011. https://doi.org/10.1146/annurev-clinpsy-032210-104535.

26. Magidson JF, Roberts BW, Collado-Rodriguez A, Lejuez CW. Theory-driven intervention for changing personality: expectancy value theory, behavioral activation, and conscientiousness. Dev Psychol. 2014; https://doi.org/10. 1037/a0030583.

27. Gassmann D, Grawe K. Ressourcenorientierte Psychotherapie - Schwerpunkt Soziale Ressourcen. In: Röhrle B, Laireiter T, editors. Soziale Unterstützung und Psychotherapie: Fortschritte der Gemeindepsychologie und Gesundheitsförderung. Tübingen: DGVT Verlag; 2009. p. 99-122.

28. Risch AK, Wilz G. Ressourcentagebuch: Verbesserung der Emotionsregulation und der Ressourcenrealisierung durch therapeutisches Schreiben im Anschluss an eine Psychotherapie. Z Klin Psychol Psychother (Gott). 2013; https://doi.org/10.1026/1616-3443/a000181.

29. Flückiger C, Wüsten G, Zinbarg R, Wampold B. Resource activation: using clients' own strengths in psychotherapy and counseling. Göttingen: Hogrefe Publishing; 2010.

30. McAdams DP. What do we know when we know a person? J Pers. 1995; https://doi.org/10.1111/1467-6494.ep9510042296.

31. Enock PM, McNally RJ. How mobile apps and other web-based interventions can transform psychological treatment and the treatment development cycle. Behav Ther (N Y N Y). 2013;36(3):56-66.

32. Klasnja P, Pratt W. Healthcare in the pocket: mapping the space of mobilephone health interventions. J Biomed Inform. 2013; https://doi.org/10.1016/j. jbi.2011.08.017.

33. Künzler F, Kramer J, Kowatsch T. Efficacy of mobile context-aware notification management systems: a systematic literature review and metaanalysis. Paper presented at the IEEE 13th International Conference on Wireless and Mobile Computing, Networking and Communications (WiMob). Rome; 2017; doi:https://doi.org/10.1109/wimob.2017.8115839

34. Marsch LA, Lord SE, Dallery J. Behavioral health care and technology: using science-based innovations to transfer practice. Oxford: Oxford University Press; 2015.

35. Miller G. The smartphone psychology manifesto. Perspect Psychol Sci. 2012; https://doi.org/10.1177/1745691612441215.

36. Schembre SM, Liao Y, Robertson MC, Dunton GF, Kerr J, Haffey ME, et al. Just-in-time feedback in diet and physical activity interventions: systematic review and practical design framework. JMIR. 2018; https://doi.org/10.2196/ jmir.8701.

37. Schueller SM, Muñoz RF, Mohr DC. Realizing the potential of behavioral intervention technologies. Curr Dir Psychol Sci. 2013; https://doi.org/10. $1177 / 0963721413495872$

38. Wahle F, Kowatsch T, Fleisch E, Rufer M, Weidt S. Mobile sensing and support for people with depression: a pilot trial in the wild. JMIR Mhealth Uhealth. 2016; https://doi.org/10.2196/mhealth.5960.

39. Harvey EJ, Rubin LF, Smiley SL, Zhou Y, Elmasry H, Pearson JL. Mobile phone ownership is not a serious barrier to participation in studies: descriptive study. JMIR Mhealth Uhealth. 2018; https://doi.org/10.2196/mhealth.8123.

40. Kowatsch T, Nißen MK, Shih I, Rüegger D, Volland D, Filler A, et al. Textbased healthcare chatbots supporting patient and health professional teams: preliminary results of a randomized controlled trial on childhood obesity, persuasive embodied agents for behavior change (PEACH2017) workshop. Co-located with the 17th International Conference on Intelligent Virtual Agents (IVA 2017). Stockholm; 2017: doi:https://doi.org/10.3929/ethzb-000218776.

41. Shih I, Volland D, Rüegger D, Künzler F, Barata F, Filler A, et al. Therapy adherence of obese children in a 6-month high-frequency intervention. Lucerne: Poster presented at the CSS health insurance meets CDHI Event; 2017. https://doi.org/10.3929/ethz-b-000221259.

42. Beun RJ, Fitrianie S, Griffioen-Both F, Spruit S, Horsch C, Lancee J, et al. Talk and tools: the best of both worlds in mobile user interfaces for e-coaching. Pers Ubiquitous Comput. 2017; https://doi.org/10.1007/s00779-017-1021-5.

43. Kowatsch T, Volland D, Shih I, Rüegger D, Künzler F, Barata F, et al. Design and evaluation of a mobile chat app for the open source behavioral health intervention platform MobileCoach, In: Maedche A, Vom Brocke J, Hevner A, editors. Designing the digital transformation. DESRIST 2017. Lecture Notes in Computer Science. Berlin; Germany: Springer; 2017. https://doi.org/10.1007/ 978-3-319-59144-5_36. 
44. Bickmore TW, Schulman D, Sidner CL. A reusable framework for health counseling dialogue systems based on a behavioral medicine ontology. J Biomed Inform. 2011; https://doi.org/10.1016/j.jbi.2010.12.006.

45. Cassell J, Sullivan J, Churchill E. Embodied conversational agents. Boston: MIT Press; 2000.

46. Ebling MR. Can cognitive assistants disappear? IEEE Pervasive Comput. 2016; https://doi.org/10.1109/MPRV.2016.41.

47. Miner AS, Milstein A, Schueller S, Hegde R, Mangurian C, Linos E. Smartphone-based conversational agents and responses to questions about mental health, interpersonal violence, and physical health. JAMA Intern Med. 2016; https://doi.org/10.1001/jamainternmed.2016.0400.

48. Provoost S, Lau HM, Ruwaard J, Riper H. Embodied conversational agents in clinical psychology: a scoping review. J Med Internet Res. 2017; https://doi. org/10.2196/jmir.6553.

49. Kowatsch T, Nißen MK, Rüegger D, Stieger M, Flückiger C, Allemand M, von Wangenheim F. The impact of interpersonal closeness cues in text-based healthcare chatbots on attachment bond and the desire to continue interacting: an experimental design. Paper presented at the 26th European Conference on Information Systems (ECIS), Portsmouth, UK; 2018

50. Reeves B, Nass C. The media equation: how people treat computers, television, and new media like real people and places. Cambridge: CSLI Publications and Cambridge University Press; 1996.

51. Flückiger $C$, Del Re $A C$, Horvath $A O$, Wampold $B E$. The alliance in adult psychotherapy: a meta-analytic synthesis. Psychotherapy. 2018; https://doi. org/10.1037/pst0000172.

52. Horvath AO, Greenberg LS. The working alliance: theory, research, and practice (Vol. 173). New York: John Wiley \& Sons; 1994.

53. Martin DJ, Garske JP, Davis MK. Relation of the therapeutic alliance with outcome and other variables: a meta-analytic review. J Couns Psychol. 2000; https://doi.org/10.1037/0022-006X.68.3.438.

54. Bickmore TW, Picard RW. Establishing and maintaining long-term humancomputer relationships. ACM Trans Comput Hum Interact. 2005; https://doi. org/10.1145/1067860.1067867.

55. Bickmore T, Schulman D, Yin L. Maintaining engagement in long-term interventions with relational agents. Appl Artif Intell. 2010; https://doi.org/ 10.1080/08839514.2010.492259.

56. Turner JC, Hogg MA, Oakes PJ, Reicher SD, Wetherell MS. Rediscovering the social group: a self-categorization theory. Cambridge: Basil Blackwell; 1987.

57. Sah YJ, Peng W. Effects of visual and linguistic anthropomorphic cues on social perception, self-awareness, and information disclosure in a health website. Comput Human Behav. 2015; https://doi.org/10.1016/j.chb.2014.12.055.

58. Haug S, Paz Castro R, Kowatsch T, Filler A, Dickson-Spillmann M, Dey M, Schaub MP. Efficacy of a web- and text messaging-based intervention to reduce problem drinking in adolescents: results of a cluster-randomised controlled trial. J Consult Clin Psychol. 2017; https://doi.org/10.1037/ ccp0000138

59. Soto CJ, John OP. The next Big Five Inventory (BFI-2): developing and assessing a hierarchical model with 15 facets to enhance bandwidth, fidelity, and predictive power. J Pers Soc Psychol. 2017; https://doi.org/10. 1037/pspp0000096.

60. Brunstein JC. Persönliche Ziele und Handlungs- versus Lageorientierung. J Individ Differ. 2001; https://doi.org/10.1024//0170-1789.22.1.1.

61. Soto CJ, John OP. Short and extra-short forms of the Big Five Inventory-2: the BFI-2-S and BFI-2-XS. J Res Pers. 2017; https://doi.org/10.1016/j.jrp.2017.02.004.

62. Lutz W, Tholen S, Schürch E, Berking M. Reliabilität von Kurzformen gängiger psychometrischer Instrumente zur Evaluation des therapeutischen Fortschritts in Psychotherapie und Psychiatrie. Diagnostica. 2006; https://doi. org/10.1026/0012-1924.52.1.11.

63. Hautzinger M, Bailer M. Allgemeine Depressionsskala. Beltz: Weinheim; 1993.

64. Dweck CS. Self-theories: their role in motivation, personality and development. Philadelphia: Taylor \& Francis/Psychology Press; 1999.

65. Diener ED, Emmons RA, Larsen RJ, Griffin S. The satisfaction with life scale. J Psychol Assess. 1985; https://doi.org/10.1207/s15327752jpa4901_13.

66. Rosenberg M. Society and adolescent self-image. Princeton University Press: Princeton; 1965.

67. Hatcher RL, Gillaspy JA. Development and validation of a revised shor version of the working alliance inventory. Psychother Res. 2006; https://doi. org/10.1080/10503300500352500.

68. Kiluk BD, Serafini K, Frankforter T, Nich C, Carroll KM. Only connect: the working alliance in computer-based cognitive behavioral therapy. Behav Res Ther. 2014; https://doi.org/10.1016/j.brat.2014.10.003.
69. Bartneck C, Kulić D, Croft E, Zoghbi S. Measurement instruments for the anthropomorphism, animacy, likeability, perceived intelligence, and perceived safety of robots. Int J Soc Robot. 2009; https://doi.org/10.1007/ s12369-008-0001-3.

70. McKnight DH, Choudhury V, Kacmar C. Developing and validating trust measures for e-commerce: an integrative typology. Inf Syst Res. 2002; https://doi.org/10.1287/isre.13.3.334.81.

71. Aron A, Aron EN, Smollan D. Inclusion of other in the self scale and the structure of interpersonal closeness. J Pers Soc Psychol. 1992; https://doi. org/10.1037/0022-3514.63.4.596.

72. Gächter S, Starmer C, Tufano F. Measuring the closeness of relationships: comprehensive evaluation of the inclusion of the other in the self scale. PLoS One. 2015; https://doi.org/10.1371/journal.pone.0129478.

73. Govern JM, Marsch LA. Development and validation of the situational selfawareness scale. Conscious Cogn. 2001; https://doi.org/10.1006/ccog.2001.0506.

74. Wixom BH, Todd PA. A theoretical integration of user satisfaction and technology acceptance. Inf Syst Res. 2005; https://doi.org/10.1287/isre.1050.0042.

75. Pollak JP, Adams P, Gay G. PAM: a photographic affect meter for frequent, in situ measurement of affect. In: In Proceedings of the SIGCHI conference on human factors in computing systems. Vancouver BC: ACM; 2011. https:// doi.org/10.1145/1978942.1979047.

76. Chittaranjan G, Blom J, Gatica-Perez D. Who's who with big-five: analyzing and classifying personality traits with smartphones. In Wearable Computers (ISWC), 15th Annual International Symposium on IEEE. 2011; doi:https://doi. org/10.1109/ISWC.2011.29.

77. Rüegger D, Stieger M, Flückiger C, Allemand M, Kowatsch, T. Leveraging the potential of personality traits for digital health interventions: a literature review on digital markers for conscientiousness and neuroticism. In 11th Mediterranean Conference on Information Systems (MCIS). Genoa; 2017; doi: 10.3929/ethz-b-000218434.

78. Filler A, Kowatsch T, Haug S, Wahle F, Staake T, Fleisch E. MobileCoach: a novel open source platform for the design of evidence-based, scalable and low-cost behavioral health interventions - overview and preliminary evaluation in the public health context. Paper presented at the 14th annual Wireless Telecommunications Symposium (WTS 2015). New York; 2015; doi: https://doi.org/10.1109/WTS.2015.7117255.

79. Nahum-Shani I, Hekler EB, Spruijt-Metz D. Building health behavior models to guide the development of just-in-time adaptive interventions: a pragmatic framework. Health Psychol. 2015; https://doi.org/10.1037/ hea0000306.

80. Nahum-Shani I, Smith SN, Spring BJ, Collins LM, Witkiewitz K, Tewari A, et al. Just-in-time adaptive interventions (JITAls) in mobile health: key components and design principles for ongoing health behavior support. Ann Behav Med. 2016; https://doi.org/10.1007/s12160-016-9830-8.

81. Bolger N, Laurenceau J-P. Intensive longitudinal methods: an introduction to diary and experience sampling research. New York: Guilford Press; 2013.

82. Little TD. Longitudinal structural equation modeling. New York: Guilford Press; 2013.

83. Nezlek JB. Multilevel modeling for social and personality psychology. London: Sage Publications, Ltd; 2011.

84. Raudenbush SW, Bryk AS. Hierarchical linear models: applications and data analysis methods (Vol. 1). California: Sage Publications, Inc; 2002.

85. Muthén LK, Muthén BO. Mplus: statistical analysis with latent variables: user's guide. Los Angeles: Muthén \& Muthén; 2010. p. 1998-2007.

86. Ozer DJ, Benet-Martinez V. Personality and the prediction of consequential outcomes. Annu Rev Psychol. 2006; https://doi.org/10.1146/annurev.psych. 57.102904.190127.

87. Roberts BW, Kuncel NR, Shiner R, Caspi A, Goldberg LR. The power of personality: the comparative validity of personality traits, socioeconomic status, and cognitive ability for predicting important life outcomes. Perspect Psychol Sci. 2007; https://doi.org/10.1111/j.1745-6916.2007.00047.

88. Cuijpers P, Smit F, Penninx BW, de Graaf R, ten Have M, Beekman AT. Economic costs of neuroticism: a population-based study. Arch Gen Psychiatry. 2010; https://doi.org/10.1001/archgenpsychiatry.2010.130.

89. Malhotra NK, Kim SS, Agarwal J. Internet users' information privacy concerns (IUIPC): the construct, the scale, and a causal model. Inf Syst Res. 2004; https://doi.org/10.1287/isre.1040.0032.

90. Collier JE, Sherrell DL. Examining the influence of control and convenience in a self-service setting. J Acad Mark Sci. 2010; https://doi.org/10.1007/ s11747-009-0179-4. 